\title{
Cultivo itinerante na Amazônia central: manejo tradicional e transformações da paisagem
}

\section{Shifting cultivation in central Amazon: traditional management and landscape transformations}

Fernanda Maria de Freitas Viana - Instituto de Desenvolvimento Sustentável Mamirauá. MSc. em Ecologia, Universidade Federal de Juiz de Fora, Minas Gerais. E-mail: fefreitasbio@gmail.com

Angela May Steward - Instituto de Desenvolvimento Sustentável Mamirauá. Ph.D. em Biologia/Etnobotânica, Graduate Center, City University of New York, Estados Unidos. E-mail: angelasteward@gmail.com

Bárbara Tadzia Trautman Richers - MSc. em Agrofloresta Tropical, Centro Agronómico Tropical de Investigación y Enseñanza, CATIE. E-mail: btadzia@gmail.com

\section{Resumo}

As regiões de florestas tropicais estão em constantes transformações, em parte, resultantes do manejo por populações tradicionais aonde os sistemas de cultivo itinerante (agricultura migratória e de corte queima) desempenham um importante papel. No entanto, juntamente a estas discussões, são questionados os impactos e a sustentabilidade destes sistemas de cultivo e suas contribuições para o desmatamento. Diante disso, procuramos maiores informações sobre a prática da agricultura migratória por meio do estudo do uso e conversão de hábitat florestal em unidades produtivas agrícolas de duas comunidades tradicionais situadas em áreas de terra firme. Concluímos que indicativos da sustentabilidade desse sistema estão associados à prática integrada à floresta e ao período destinado ao pousio das áreas.

\section{Palavras-chave}

Agricultura migratória. Comunidades tradicionais. Conversão florestal. Corte e queima. Desmatamento. Amazônia Central.

\begin{abstract}
Tropical forest regions are in constant transformation, partly resulting from management by traditional populations where shifting cultivation systems (swiddenfallow and slash and burn agriculture) play an important role. However, along with these discussions, the impacts and sustainability of these farming systems and its contribution to deforestation are often called into question. Therefore, this research sought to generate information on the practice of shifting cultivation by studying the conversion of forest habitat to agricultural areas located in two traditional communities in upland areas of Central Amazonia. We conclude that the sustainability of this system is based on its character of being integrated into surrounding forests and the length of the fallow period maintained by farmers who engage in this practice.
\end{abstract}

\section{Keywords}

Shifting agriculture. Traditional communities. Forest conversion. Slash and Burn. Deforestation. Central Amazônia. 


\section{INTRODUÇÃO}

A região tropical do planeta apresenta atualmente uma grande extensão de cobertura de vegetação composta por florestas secundárias, resultantes das transformações na paisagem que vem ocorrendo ao longo de milhares de anos. Frequentemente estas transformações estão vinculadas a diversos tipos de usos do solo que têm como principal finalidade o estabelecimento de sistemas agrícolas e pastagens (BRANCALION et al., 2012; CHAZDON, 2012; MASSOCA et al., 2012).

Práticas de cultivo itinerante, como os sistemas de agricultura migratória (shifting cultivation) e corte e queima (slash and burn), adotadas por comunidades tradicionais, consistem em formas de agricultura tradicional, onde são abertas áreas de vegetação primária (mata bruta) ou secundária (capoeira) para o estabelecimento de sistemas de produtivos, com cultivos que duram períodos menores do que o tempo que estas áreas permanecem em pousio (KLEINMAN et al., 1995; PEDROSO JUNIOR et al., 2008).

Nestes dois tipos de sistemas é realizada a abertura e queima de pequenos fragmentos de mata para o estabelecimento dos cultivos. Apesar da queima ser uma prática comum no processo de abertura de áreas, algumas áreas de plantio podem ser estabelecidas sem esta prática (PINEDO-VAZQUEZ et al., 1996; RICHERS, 2010).

$\mathrm{Na}$ agricultura migratória são estabelecidos sistemas de cultivo temporários sendo estes intercalados com períodos de pousio mais longos, permitindo o início da regeneração da vegetação. No sistema corte e queima, por outro lado, o período de pousio quando é adotado, é praticado por curtos períodos, dificultando o restabelecimento vegetação e como resultado a floresta é convertida em campos permanentes (de cultivo ou pastagem) (SANCHEZ et al. 2005; VAN VLIET et al., 2013).

Comumente encontramos na literatura estes dois termos sendo tratados como sinônimos (SANCHEZ et al. 2005; PEDROSO JUNIOR et al., 2008; MERTZ et al., 2009). No entanto, com as mudanças nos padrões de uso observadas mais recentemente, principalmente no que se refere às variações da intensidade de uso do solo, nos períodos de pousio e distribuição das terras destinadas a agricultura familiar (em assentamentos, colônias agrícolas e Terras Indígenas), observou-se a tendência a utilização de períodos de pousio mais curtos e a intensificação de uso do solo em algumas regiões (METZGER, 2002). Entretanto, pode-se dizer que a principal diferença entre estes dois sistemas refere-se principalmente ao período de pousio entre o estabelecimento de novas áreas de roça. Esta breve comparação assinala a complexidade das diferentes 
formas de uso e o seu impacto sobre a paisagem, ecossistemas e seus recursos naturais, onde esta prática é comumente utilizada.

Estudos recentes destacam os altos níveis de agrobiodiversidade favorecidos pelo manejo destas áreas (EMPERAIRE e ELOY, 2008; PEDROSO JUNIOR et al., 2008; PADOCH e PINEDO-VASQUEZ, 2010; LIMA et al., 2012; LIMA et al., 2013; NODA et al., 2012; ROBERT et al., 2012). Estes sistemas são os mais difundidos entre as diversas famílias de pequenos agricultores (PEDROSO JUNIOR et al., 2008; RICHERS, 2010) onde incluem-se diferentes grupos de agricultores familiares (indígenas, ribeirinhos, assentados, colonos, etc.) da região amazônica (FEARNSIDE, 1989; BRADY, 1996; ADAMS et al. 2006; PEDROSO JUNIOR et al., 2008). Em torno de 35 milhões e um bilhão de pessoas sobrevivem desses sistemas de cultivo (KLEINMAN et al., 1996; NEVES et al., 2012; RIBEIRO FILHO et al., 2013).

Apesar das áreas de vegetação secundária (capoeiras) serem constantemente reutilizadas para o estabelecimento de novos sistemas de roças, como ocorre na agricultura migratória, os impactos desta atividade ainda são alvos de discussão entre pesquisas no intuito de se compreender seus impactos em áreas tropicais, especialmente no contexto do desmatamento na Amazônia (MYERS, 1993; BRADY, 1996; METZGER, 2002; PEDROSO JUNIOR et al., 2008; RICHERS, 2010). Estudos sobre estes sistemas de cultivo aumentaram nos últimos anos (RIBEIRO FILHO et al., 2013) além das discussões sobre o estado e futuro de comunidades de pequenos agricultores que praticam a agricultura itinerante (PADOCH e PINEDO-VASQUEZ, 2010) e suas relações com as mudanças climáticas, aquecimento global e as políticas de redução das emissões de carbono (FEARNSIDE, 2005; 2006; BRANCALION et al., 2012; CHAZDON, 2012). Entretanto, este tipo de prática ainda apresenta uma invisibilidade no sentido de entender como ela é praticada em contextos diferentes (i.e. ecossistemas e ambientes diferentes, contextos fundiários diferenciados, regiões específicas, além de outros parâmetros socioeconômicos) (MERTZ et al., 2009; PADOCH e PINEDO-VASQUEZ, 2010; RIBEIRO-FILHO et al., 2013), bem como a reduzida informação sobre as mudanças e tendências da prática de agricultura itinerante entre pequenos agricultores (VAN VLIET et al., 2013).

Pesquisas sobre os padrões de uso do solo e os impactos sobre a floresta vem sendo conduzidas no intuito de se conhecer melhor a relação entre estes aspectos. Neste contexto, as formas de agricultura itinerante (migratória e corte e queima) vêm sendo debatidas, principalmente quanto ao seu papel nas taxas de desmatamento no intuito de se compreender mais amplamente a sustentabilidade destas práticas (PEDROSO JUNIOR et al. 2008; RIBEIRO FILHO et al., 2013; 
VAN VLIET et al., 2013). Pesquisas demonstram que, em geral, os maiores impactos de desmatamento são verificados associados à agricultura convencional, ao estabelecimento de campos de pastagens e estabelecimento de culturas de soja ou outras monoculturas de larga escala, além da abertura de rodovias e estradas que promovem alterações relevantes no ecossistema florestal (FEARNSIDE, 2003; LAURANCE et al., 2004; FERREIRA et al., 2005; RIVERO et al., 2009).

De forma geral, os impactos negativos das práticas de agricultura itinerante são encontrados na fase de conversão (corte-derruba-queima) da floresta e referem-se principalmente aos impactos sobre o solo e uso do fogo. A fase de pousio, por outro lado, está associada aos impactos positivos, por ser nesta fase que se reproduzem os processos ecológicos semelhantes aos dos ecossistemas florestais (RIBEIRO FILHO et al., 2013). Embora algumas práticas de corte e queima em circunstâncias particulares ${ }^{1}$, estejam associadas ao aumento e redução das taxas de conversão de hábitat florestais, na região de floresta amazônica, estes sistemas têm assegurado a subsistência destas populações por milhares de anos (POSEY, 1997; PEREIRA, et al., 2010; ROBERT e LÓPEZ, 2012), sendo uma das mais importantes formas de uso dos recursos florestais e do solo desta região, responsáveis pela preservação de um patrimônio cultural e genético que ainda deve ser melhor conhecido.

Neste contexto, buscamos contribuir para a geração destas informações apresentando as particularidades da agricultura migratória praticada em comunidades ribeirinhas que têm a atividade agrícola como uma das principais atividades econômicas. Iniciamos a discussão apresentando uma caracterização das comunidades escolhidas associando seus diferentes perfis às atividades desenvolvidas e às formas de manejo do solo. Partimos desta caracterização para compreender as práticas de manejo dos agricultores através de um estudo do histórico de transformação dos espaços agrícolas ao redor das comunidades estudadas e estabelecemos relações com análises espaciais, levando em consideração a história das famílias e práticas adotadas.

Pensamos que as formas de manejo das áreas agrícolas, o nível de especialização das comunidades na produção de farinha, e as estratégias de economia doméstica, bem como aspectos socioeconômicos como o recebimento de benefícios (Bolsa Família, Bolsa Floresta e Seguro Defeso) (PERALTA e LIMA, 2013) podem ter influências nas variações das taxas da agricultura migratória praticada nos padrões de abertura de florestas primárias (mata bruta)

Aqui se refere em particular aos pequenos agricultores que praticam agricultura corte queima e que habitam áreas de assentamento estabelecidas por políticas de reforma agrária na Amazônia (veja FEARNSIDE, 2005). 
ou secundárias (capoeiras) para fins agrícolas. Além disso, sugerimos que a agrobiodiversidade encontrada nestas comunidades é resultado dos diferentes perfis observados e que as técnicas utilizadas promovem uma utilização de reduzido impacto quando comparadas com agricultura convencional que é praticada em larga escala para fins lucrativos.

Esta pesquisa apresenta uma contribuição ao conhecimento da dinâmica da agricultura migratória em regiões tropicais, trazendo informações sobre o desenvolvimento da atividade agrícola em comunidades tradicionais e suas relações com os impactos ambientais e modificações na paisagem debatidos atualmente, bem como as perspectivas futuras para as comunidades inseridas neste mesmo contexto. Com diferentes perfis, o estudo destas comunidades traz percepções que auxiliam no debate da sustentabilidade destas práticas, e contribui para as discussões sobre o papel da agricultura migratória nas variações das taxas de conversão de hábitat florestais em áreas agrícolas.

\title{
METODOLOGIA
}

\author{
Área de estudo
}

Esta pesquisa foi desenvolvida em duas comunidades de terra firme, sobre solos de paleovárzea ${ }^{2}$ dentro da Reserva de Desenvolvimento Sustentável Amanã (RDSA), Amazonas. A reserva for criada pelo decreto 19,021/98 conforme as definições e normas do Sistema Nacional da Unidade de Conservação (SNUC) para unidades de conservação de uso sustentável.

A RDSA é localizada na região do Médio Solimões, entre as bacias do Rio Negro e Rio Solimões. Detém uma área de aproximadamente, 2.350.000 ha sendo formada por ambientes de terra firme, paleovárzea, igapó e matas de várzea, com trechos de campina e campinarana (VALSECCHI e AMARAL, 2009; IRION et al., 2011). Inclui terras que pertencem aos municípios de Maraã, Coari, Barcelos e Codajás e compõe juntamente com a Reserva de Desenvolvimento

\footnotetext{
A Reserva de Desenvolvimento Sustentável Amanã abrange áreas de várzea, paleovárzea e terra firme entre outros ambientes; áreas de várzea são sujeitas a inundações anuais onde as atividades agrícolas são organizadas levando-se em conta as variações em torno da dinâmica das enchentes. As áreas de terra firme, por outro lado, geralmente escapam das enchentes anuais devido a sua elevação ligeiramente superior. Áreas de paleovárzea são zonas intermediárias que pertencem a formações geológicas mais antigas das várzeas e mais recentes das áreas de terra firme. Áreas de paleovárzea estão sujeitas a inundações eventuais particularmente em anos de alagações grandes. A reclassificação recente dos ambientes da região Médio Solimões (IRION et al., 2011) contempla a ideia de que o arranjo de espécies pode ser diferenciado nas paleovárzeas, quando comparadas as áreas de várzea desta mesma região. Localmente moradores referem-se a áreas de paleovárzea como "terra firme".
} 
Sustentável Mamirauá (RDSM) e com o Parque Nacional do Jaú um dos maiores corredores de floresta tropical protegida do mundo (PEREIRA et al., 2010) com aproximadamente 6.500.000 ha (QUEIROZ, 2005; QUEIROZ e PERALTA, 2006). Os moradores são em sua maioria pequenos agricultores e pescadores e constituem comunidades tradicionais ribeirinhas ${ }^{3}$, que tem como principais meios de subsistência a agricultura, a pesca, a caça e o extrativismo. Em média o número de habitantes da área focal da RDSA é em torno de 3.860 habitantes distribuídos em 86 localidades (IDSM, 2011).

A pesquisa foi desenvolvida em duas comunidades entre os anos de 2009 e 2010 na comunidade de Boa Esperança, e em 2012 na comunidade de Nova Jerusalém. (Figura 1).

Figura 1 - Localização das comunidades abordadas no estudo - Reserva de Desenvolvimento Sustentável Amnã, AM.
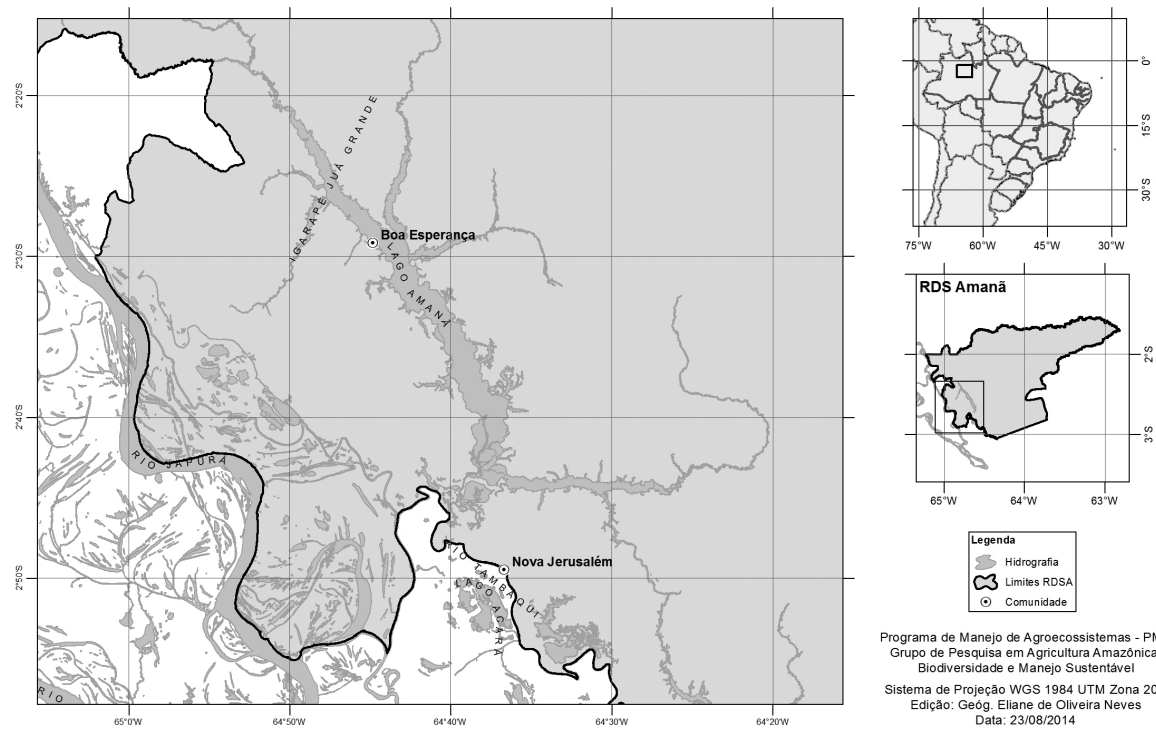

Programa de Manejo de Agroecossistemas - PMA Grupo de Pesquisa em Agricultura Amazônica, Blodiversidade e Manejo Sustentavel Sistema de Projeçāo WGS 1984 UTM Zona 20 S
Edição: Geóg Eliane de Oliveira Neves Ediçăo: Geóg. Eliane de Oliveila
Data: $23 / 08 / 2014$

A primeira comunidade estudada é Boa Esperança (-2,47719; -64,76094) que se localiza na cabeceira do Lago Amanã, em ambientes de paleovárzea, referidos localmente como áreas de "terra firme" (áreas que não alagam anualmente). A comunidade é composta por aproximadamente 252 pessoas (IDSM, 2011) distribuídas em 55 residências, sendo a maior comunidade dentro

\footnotetext{
Os moradores da RDSA pertencem ao campesinato amazônico, os ribeirinhos (referidos também na literatura Amazônica como os caboclos), cuja origem é pós-colonial, e que residem historicamente nas margens dos rios. Também são populações tradicionais por residir dentro de uma unidade de conservação de uso sustentável e de ser uma população com uma longa historia de convivência no ambiente Amazônico (LIMA, 2006).
} 
desta reserva. A quase totalidade dos moradores tem a agricultura e o cultivo de frutíferas como a principal atividade produtiva da economia doméstica para fins de subsistência e venda, sendo a produção de farinha voltada principalmente para a venda (VENTURATO e PEREIRA, 2010; PERALTA e LIMA, 2013). A caça e a pesca também são atividades desenvolvidas nesta comunidade, entretanto são voltadas exclusivamente para a subsistência das famílias (VALSECCHI e AMARAL, 2009). Em campo também observamos a coleta de materiais da floresta (madeira, espécies oleoginoasas) para o uso doméstico, como o fruto e sementes de castanhas e andiroba e a extração de madeira (voltada principalmente para atender as demandas dos moradores nas construções de casas, canoas, barcos, móveis e utensílios utilizados na agricultura e pesca).

A segunda comunidade, Nova Jerusalém (-2,82437; -64,61048) está localizada às margens do rio Tambaqui, e é formada por ambientes de várzea, paleovárzea e de terra firme. As áreas de várzea próximas à comunidade localizam-se fora dos limites da RDSA, já as áreas de terra firme estão localizadas na área focal da reserva. A pesquisa foi desenvolvida apenas nas áreas de terra firme dentro dos limites da reserva. Esta comunidade tem aproximadamente 231 moradores (IDSM, 2011); que atualmente se distribuem em 38 residências, sendo a segunda maior comunidade em número de habitantes desta reserva. A principal atividade desenvolvida é a pesca, seguida pela atividade agrícola e pela caça (VALSECCHI e AMARAL, 2009), que são voltadas a subsistência das famílias. A extração de madeira também foi observada na comunidade com as mesmas finalidades já mencionadas para a comunidade de Boa Esperança.

A pesquisa foi desenvolvida em três etapas. A primeira etapa consistiu em um diagnóstico inicial utilizando ferramentas de pesquisa etnográfica, onde foram realizadas entrevistas semiestruturadas com os pequenos agricultores (BERNARD, 2011). Neste momento, procurou-se investigar aspectos sobre o processo de abertura da floresta para fins agrícolas, uso destas áreas, formas de manejo tradicional e diversidade produtiva. $\mathrm{Na}$ segunda etapa foram realizadas visitas as unidades produtivas (áreas de roça, sítio, quintais e capoeiras em pousio até quatro anos de idade), juntamente com o agricultor, para o georeferenciamento destas áreas em campo. A terceira etapa consistiu na sistematização destas informações em um banco de dados, sendo estas utilizadas para confecção de polígonos das áreas de uso agrícola mapeadas em campo. Foi realizada uma sobreposição destas áreas com as imagens do satélite Landsat5 dos anos de 2000, 2005 e 2011 e através das imagens foi realizada a delimitação das áreas de uso (agrícola e para outros fins), em escala determinada, onde se verificou as transformações na paisagem por meio da conversão florestal em áreas de uso das comunidades. 


\section{RESULTADOS}

\section{Sistemas agrícolas e as características da agricultura migratória na área de estudo}

Nas últimas décadas as comunidades da RDSA localizadas em áreas que não sofrem alagações periódicas (terra firme e paleovárzea) têm sido utilizadas para plantio da mandioca (Manibot esculenta Crantz), com objetivo principal na produção de farinha para subsistência e venda local e para o plantio de cultivos diversificados de frutíferas, com fins de comercialização e consumo local.

Em ambientes de terra firme e paleovárzea, o período disponível para o uso do solo é em torno de 1 a 2 anos, quando as áreas não estão expostas às alagações sazonais, consequentemente os agricultores podem investir em variedades de mandioca mais duradouras, e as famílias dedicam um período maior ao cultivo nestas áreas, experimentando um grande número de variedades e em áreas maiores do que as de várzea (LIMA et al., 2012). As áreas de terra firme, não são expostas a fertilização natural periodicamente, com isso a produtividade dos solos tende a reduzir com o passar dos anos, o que ocasiona no abandono da área em pousio, pelos agricultores, para que a área adquira novamente condições adequadas para o estabelecimento de um novo ciclo produtivo (PEREIRA et al., 2010).

Os sistemas de produção são diferenciados nas áreas de várzea, onde os agricultores têm de se atentar para o plantio de espécies de ciclo curto, pois a variação sazonal, em torno de 6 meses, não favorece o plantio de espécies de ciclo reprodutivo mais longo e que não sejam resistentes a água. (LIMA et al., 2012).

O período dedicado a fase de cultivo favorece a especialização das comunidades na produção familiar, como é o caso da comunidade de Boa Esperança onde os moradores, além do cultivo da mandioca, investem na diversidade de plantio de frutíferas e hortaliças, o que enriquece a base do consumo de alimentos pelos moradores e permite a comercialização de uma variedade de produtos que contribuem com a renda familiar.

O uso dos recursos pelos moradores e a formas de ocupação do espaço nas comunidades são principalmente voltados para a produção agrícola, de onde as famílias retiram o essencial para subsistência e destinam o excedente ao mercado regional. A agricultura permanece de caráter familiar, com práticas locais diversificadas que incluem o uso de técnicas de baixo impacto e de utensílios fabricados pelos moradores para a produção com a mais recente integração do uso da motoserra utilizada para estabelecer novas áreas (STEWARD e LIMA, 2014). 
As formas de uso do espaço são definidas a partir do tipo de paisagem encontrada ao redor das comunidades. A paisagem é composta por um mosaico de usos do solo, denominados neste artigo pelos "tipos de uso do solo" ou land use stages $^{4}$ quais se encontram em estágios sucessionais diferentes, com temporalidades diferentes e sujeitos aos regimes distintos de manejo conforme os objetivos dos agricultores. Entre os tipos mais comuns na área de estudo verificamos: mata bruta (floresta primária), capoeira (vegetação florestal secundária), roças, sítios e quintais. As áreas de mata, bem como as áreas de capoeira são potenciais áreas de uso agrícola, e estão sob a gestão do agricultor.

A durabilidade de cada land use stage está, por diversas vezes, sujeita as variações sazonais com os períodos de cheia e vazante, e varia conforme o tipo de manejo realizado na área. De forma geral, as capoeiras e as roças são utilizadas consorciando o período de pousio intercalados com os períodos de uso. Em Boa Esperança o período médio de tempo em que as áreas de capoeira permaneceram em pousio foi de 6 anos, enquanto em Nova Jerusalém este período foi de 5,41 anos. Estes resultados corroboram dados de pesquisas realizadas em comunidades de terra firme nesta mesma região (PEREIRA et al., 2010; RICHERS, 2010) onde a variação do período de pousio encontrada foi entre 4 e 10 anos. Quintais e sítios, uma vez estabelecidos são utilizados de forma mais permanente, embora o agricultor possa decidir deixar a área se transformar em capoeira a qualquer momento ou manejá-la novamente para o estabelecimento de um roçado. Observa-se que a organização do espaço destas áreas varia conforme o regime do manejo (Tabela 1).

Tabela 1 - Características das land use stages identificadas na área de estudo

\begin{tabular}{c|l}
\hline \multicolumn{2}{c}{ Fases de uso do solo (Land use stages) } \\
\hline Mata Bruta & $\begin{array}{c}\text { área de vegetação primária ou secundária em estágio avançado de } \\
\text { regeneração (> que 10 anos), onde são estabelecidos novas áreas de roça }\end{array}$ \\
\hline Capoeira & $\begin{array}{l}\text { área de vegetação secundária, em estágio inicial (1 a 4 anos) ou médio de } \\
\text { regeneração (5 a } 10 \text { anos); correspondem a áreas já utilizadas anteriormente, } \\
\text { geralmente para o estabelecimento de roçados de mandioca }\end{array}$ \\
\hline Roçado & $\begin{array}{l}\text { área destinada maiormente ao plantio da mandioca (Manihot esculenta } \\
\text { Crantz), onde também podem ser encontrados outros cultivos como o de } \\
\text { espécies frutíferas variadas; voltada para a subsistência dos agricultores, } \\
\text { geralmente a roça tem a duração variando entre sete meses e dois anos }\end{array}$ \\
\hline
\end{tabular}

4 Land use stages refere-se aos diversificados tipos de uso do solo em que são expostas as áreas produtivas agrícolas pelos agricultores familiares que estabelecem seus cultivos nestas áreas (BROOKFIELD, 2002). Dentre as principais fases destacam-se as fases de mata bruta, de capoeiras em diferentes estágios de regeneração, os roçados de mandioca e os sítios/quintais de cultivos variados. 


\begin{tabular}{c|l}
\hline Sítio & $\begin{array}{l}\text { área destinada ao plantio de frutíferas, geralmente são antigas áreas de roça } \\
\text { e capoeiras, localizadas em locais de fácil acesso para os moradores. Na } \\
\text { grande maioria das vezes é uma área que possui uma grande diversidade } \\
\text { de espécies de interesse alimentício e medicinal. Estas áreas correspondem } \\
\text { a antigas áreas de mata ou capoeira que já foram utilizadas para o } \\
\text { estabelecimento de roças. Os sítios têm a duração longa, e geralmente } \\
\text { quando estabelecidos são destinados ao uso permanente. }\end{array}$ \\
\hline Quintal & $\begin{array}{l}\text { espaço localizadono entorno das casas, onde são cultivadas além de espécies } \\
\text { frutíferas, hortaliças e cultivos de interesse na alimentação e/ou medicinal; } \\
\text { é também um espaço de interações sociais, onde crianças brincam, local } \\
\text { para se estenderem roupas e onde algumas famílias preparam alimentos e } \\
\text { "tratam o peixe". Geralmente, são áreas que uma vez estabelecidos ficam } \\
\text { permanentemente sendo utilizadas com esta finalidade. }\end{array}$ \\
\hline
\end{tabular}

O uso da floresta (mata ou capoeira) para a agricultura, na área de estudo, variou de acordo com os diferentes ambientes e atividades econômicas praticadas, e com as histórias de ocupação em cada localidade. Boa Esperança é uma comunidade relativamente grande pelos padrões de ocupação local da RDSA. Estima-se que a ocupação desta comunidade ocorreu em 1976 (ALENCAR, 2007). Com o enfraquecimento do extrativismo vegetal (seringa, maçaranduba, castanha e sorva), causado por mudanças de mercado para a comercialização destes produtos a comunidade começou a dedicar-se à agricultura, principalmente ao cultivo de frutíferas (ALENCAR, 2010). No entanto, em seguida, houve uma intensa contaminação por pragas nas plantações de limão e banana e foi quando a comunidade passou a priorizar o cultivo da mandioca, assim como ocorreu com outras comunidades localizadas nesta região. Embora muitos agricultores tenham perdido, neste período, praticamente todos os cultivos destas espécies, o cultivo de frutíferas nos sítios, áreas de roçados e capoeiras ainda é bastante utilizado entre eles e vem sendo cada vez mais intensificado.

Hoje esta comunidade é reconhecida por sua especialização na agricultura, onde os moradores vendem com mais frequência e em mais volume. O principal cultivo é o da mandioca e a maior parte da sua produção é destinada para a comercialização da farinha; junto com o cultivo da mandioca, os agricultores mantêm uma diversidade de frutíferas, aonde se inclui, em particular, a cultura da banana, encontrada em praticamente todas as áreas produtivas cultivadas. Além disso, os cultivos de cará, abacaxi, açaí e abacate também apresentam uma importância local. Em suma, pela sua localização, em áreas que geralmente não se alagam e pelas características históricas apresentadas, a produção familiar se desenvolveu tendo a agricultura de mandioca como principal meio de desenvolvimento das famílias. 
A comunidade de Nova Jerusalém, por outro lado, tem como principal atividade econômica produtiva a pesca, sendo esta atividade uma fonte de renda mais importante do que a venda de produtos agrícolas, onde a produção de farinha é mais voltada ao consumo familiar. Apesar disso, a agricultura também se mantém como uma atividade de grande importância na comunidade. Além destas atividades a caça também é praticada entre os moradores sendo essa uma importante forma de inserção de proteína animal na alimentação dos moradores (VALSECCHI e AMARAL, 2009).

Sua estimativa de ocupação é dos anos 40, sendo uma das primeiras comunidades a serem formadas na região do rio Tambaqui (ALENCAR, 2007). Muitas famílias desta região eram procedentes de seringais e foram atraídas pela notícia da fartura de pescados e outros recursos naturais nesta região (ALENCAR, 2010). Parte de sua extensão situa-se em ambientes de várzea, onde alguns dos agricultores possuem áreas que destinaram ao plantio de bananais e estabelecimento de plantios de ciclo curto. Sua outra porção, localizada em terra firme é utilizada para o estabelecimento de áreas agrícolas mais duradouras, apesar de algumas destas áreas estarem sujeitas a alagações eventuais.

O desenvolvimento da comunidade na atividade pesqueira, além de ter sido influenciado pelas atividades extrativistas, que se reduziram com o passar dos anos, seria uma forma de complementar a alimentação para subsistência, já que foi verificada a alagação quase total das áreas produtivas, em alguns momentos. Na agricultura, o cultivo da mandioca também é o principal, embora os moradores também invistam em espécies frutíferas tais como a banana, o açaí, a pupunha e o abacate com finalidade principal de consumo próprio.

De forma geral, a produção de farinha e os outros derivados da mandioca nas comunidades, junto com as outras atividades econômicas são destinados à manutenção das famílias; os produtos agrícolas ou são consumidos direitamente pelos moradores ou vendidos localmente. Geralmente esses produtos são comercializados de três formas: na própria comunidade, para compradores externos ou em feiras regionais, como a cidade de Tefé, que se tornou um local importante para a comercialização destes produtos. Como Lima (2006) explica uma das características principais das economias domésticas ribeirinhas, na região do Médio Solimões, é a orientação das atividades à manutenção dos grupos domésticos - ou as famílias consomem diretamente a sua própria produção ou eles vendem sua produção para conseguir artigos que eles não produzem nas suas propriedades (por exemplo, alimentos industrializados, ferramentas de trabalho, entre outros bens domésticos). A lógica camponesa neste sentido se difere da lógica capitalista - a qual é orientada pela geração de lucros. 
As diferenças na história de ocupação e no uso da floresta para agricultura são refletidas na paisagem como reconstruído no mapeamento em campo e pela análise de imagens de satélite. A comunidade de Boa Esperança apresenta uma demanda maior para abertura de áreas para uso agrícola tendo em vista sua especialidade no cultivo da mandioca para a produção de farinha voltada a comercialização. Nesta comunidade cada agricultor individualmente apresenta um número médio de 5,57 áreas com uma média de 0,91 ha de área. No monitoramento realizado, entre os anos de 2009 e 2010, foram identificados os seguintes land use stages: 118,5 ha de roça, 88,4 ha de capoeiras em pousio de até 4 anos, 36,1 ha de sítios, 26,3 ha pasto (Figura 2). Sendo a área total destinada às unidades produtivas de 269,3 ha, correspondendo a 33,7 \% da área total de uso na comunidade, mapeada nas imagens.

Figura 2 - Localização dos land use stages mapeados na comunidade de Boa Esperança, Reserva de Desenvolvimento Sustentável Amanã, AM.
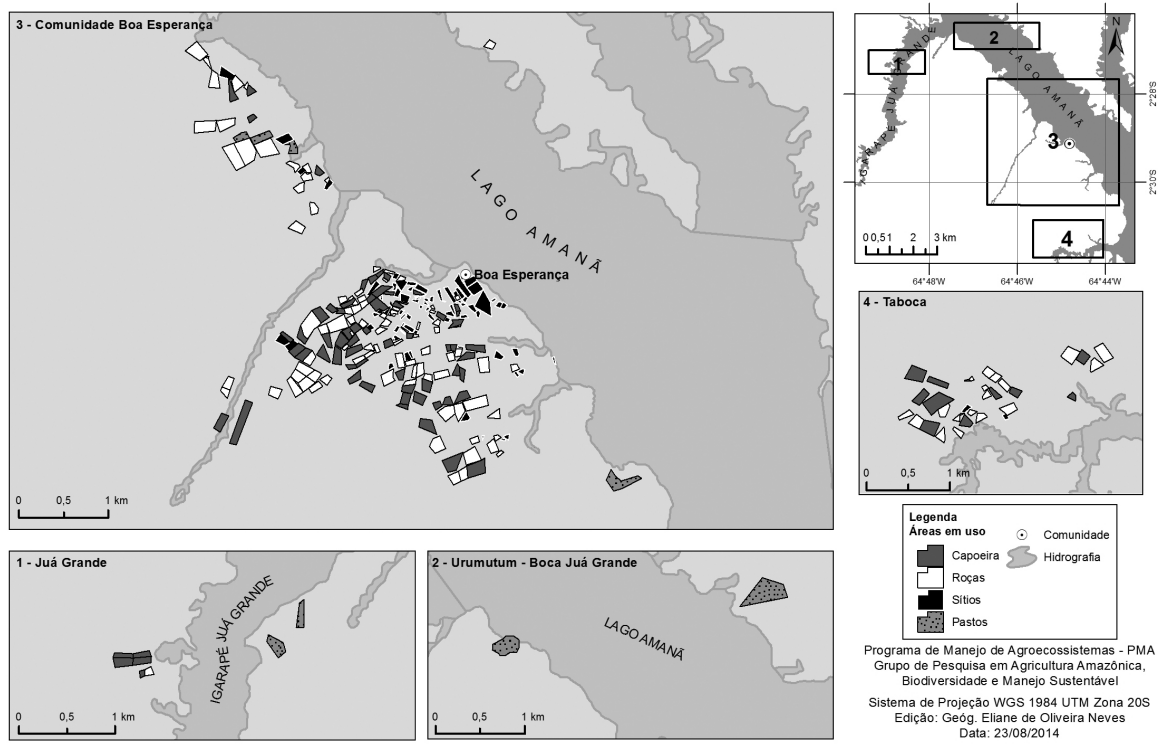

Edição: Geóg. Eliane de Oliveira Neves
Data: $23 / 08 / 2014$

Estas taxas variam ao longo dos anos de acordo com a dinâmica agrícola da comunidade. Baseando-se nos relatos dos moradores constatou-se que as primeiras aberturas de áreas para o estabelecimento das unidades produtivas ocorreram nos anos 80 e 90, sendo que a grande maioria das áreas foi aberta entre os anos de 2000 e 2010 (52,1\%). Analisando-se as imagens de satélite nesta região observou-se que a paisagem passou por transformações ao longo do tempo, sendo possível observar o histórico de alteração da cobertura florestal (Figura 3). 
Figura 3 - Gráfico de histórico de transformações da cobertura florestal em hectares (ha), verificados ao longo do tempo nas áreas de estudo.

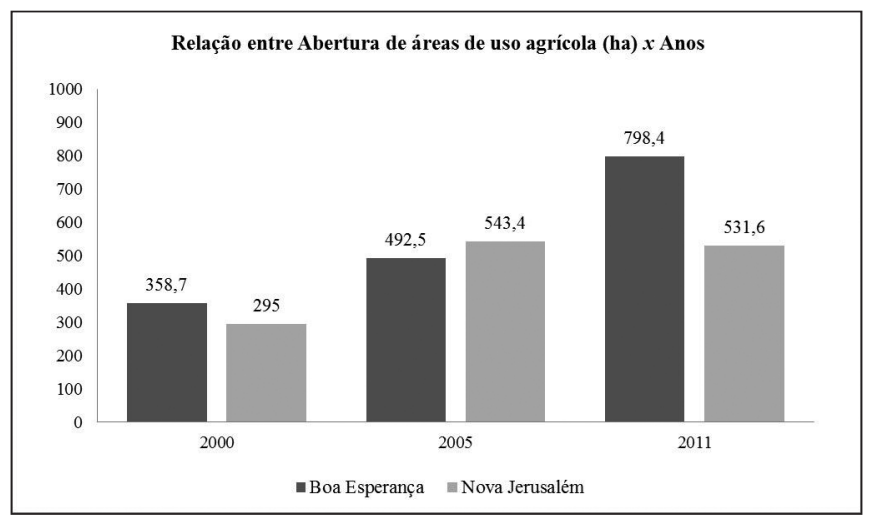

Estas análises demonstram que a área convertida, que não está em uso pode estar associada a áreas destinadas a outros tipos de uso como para a atividade pecuária ou correspondem a vegetação secundária (capoeiras) em regeneração com idades superiores a quatro anos e que, portanto, não foram mapeadas (a menos quando são retomadas para um novo estabelecimento de roças), contabilizando $66,3 \%$ do total de área convertida. Entre os fatores que possivelmente influenciaram o aumento na abertura de áreas estão o aumento da população, o processo de desenvolvimento das famílias e a especialização da produção voltada para a produção de farinha de mandioca para comercialização. Resultados dos censos demográficos realizados nesta comunidade demonstraram que em anos próximos ao que este monitoramento foi realizado a população residente foi de 162 pessoas em 2002 (IDSM, 2002), 212 pessoas em 2006 (IDSM, 2006) e 252 pessoas em 2011 (IDSM, 2011), sendo o aumento populacional proporcional as variações observadas quanto ao aumento de áreas agrícolas verificada entre os anos.

Perspectivas futuras apontam para uma tendência a estabilização no processo de abertura de áreas nesta comunidade, já que a distância das áreas de mata da comunidade é cada vez maior, a prática do reaproveitamento de florestas secundárias para o estabelecimento de cultivos é adotada entre os agricultores, e em algumas famílias há o estabelecimento de uma relação de "doação/ empréstimo/divisão" de áreas entre parentes, o que reduz o estabelecimento de cultivos em áreas de mata bruta. Isso pode ser percebido nas falas de agricultores como: "Eu trabalho de meio com meu irmão, a gente plantou essa área toda junto e depois resolvemos que cada um ficava cuidando de uma parte.." (morador da comunidade de Boa Esperança). 


\begin{abstract}
"Quando cheguei aqui eu trabalhava com agricultura na área de outras pessoas, eu plantava mais limão e outras coisas, porque ainda não tinha uma terra pra eu plantar, depois eu consegui minhas terras e hoje eu reparti a terra com meus filhos e trabalho mais junto com eles." (morador da comunidade de Boa Esperança).
\end{abstract}

As áreas de roças se destacam como o principal tipo de uso do solo (land use stage) desta comunidade e são destinadas principalmente ao plantio da mandioca ("braba") e/ou macaxeira ("mansa"), e representam a maioria das áreas utilizadas pela comunidade. Além das variedades de mandioca, são encontradas outras espécies de interesse econômico e ecológico que servem principalmente para alimentação, uso medicinal, e para extração de madeira com finalidades diversas de construção de casas, canoas e balsas e fabricação de utensílios utilizados na comunidade.

As capoeiras identificadas pelos moradores com idade de pousio entre 1 e 4 anos correspondem a áreas que tiveram sua primeira utilização entre um ano e 11 anos atrás e carregam a herança das variedades de manivas destes anos de uso, que vão sendo substituídas pelas espécies secundárias a partir do desenvolvimento desta vegetação. Nestas áreas, geralmente observamos espécies de embaúba (Cecropia spp.) e espécies frutíferas plantadas para enriquecimento das áreas e alimentação dos moradores.

Os sítios constituem áreas que foram destinadas em seus primeiros usos ao plantio de roça. Geralmente os agricultores seguem alguns critérios para a escolha do espaço para o plantio do sítio: qualidade do solo ${ }^{5}$, a presença de matéria orgânica sobre o solo, a existência de paú ${ }^{6}$, localização da área, em “terras altas 7", a localização em ambientes de fácil acesso ou próximo a áreas que são constantemente visitadas pelas famílias também são fatores que influenciam nesta escolha. Nas duas comunidades pesquisadas os sítios foram os ambientes com a maior diversidade de espécies frutíferas ${ }^{8}$.

Embora a estimativa de ocupação da comunidade de Nova Jerusalém seja dos anos 40, os moradores relatam que as primeiras áreas foram abertas nos

Ao se observar a qualidade do solo, os moradores explicam que observam o tipo de terra presente no local e se esta é apropriada ao plantio de determinada espécie.

6 Paú é uma definição que foi dada pelos agricultores a um composto formado pela queima da matéria orgânica, juntamente com a decomposição da madeira, com a terra, calor e água. Segundo os moradores a presença do paú é um indicativo de uma terra de boa produtividade daquele ambiente.

7 A expressão "terras altas" é comumente utilizada entre os moradores geralmente para definir áreas situadas em terras que não são alagadas anualmente.

8 Em 2003, Schmidt documentou um total de 57 espécies de cultivos em 87 áreas de roça em quatro comunidades de terra firme na RDSA - uma delas sendo Boa Esperança - e encontrou 68 espécies cultivadas em 67 áreas de sítio e capoeiras não manejadas nestas mesmas comunidades. 
anos 80 e 90 com maiores taxas registradas entre os anos 2000 e 2011 (41\%). Os resultados do monitoramento realizado no ano de 2012 demonstram o uso do solo como os seguintes land use stages: 37,5 ha de capoeiras em pousio até 4 anos, 9,7 ha de roça, 7,4 ha de sítios, 0,6 ha de quintais, totalizando 55,2 ha de áreas de uso agrícola, o que corresponde a 10,4\% da área total de uso da comunidade, mapeada nas imagens (Figura 4).

Figura 4 - Localização dos land use stages mapeados na comunidade de Nova Jerusalém, Reserva de Desenvolvimento Sustentável Amanã, AM.
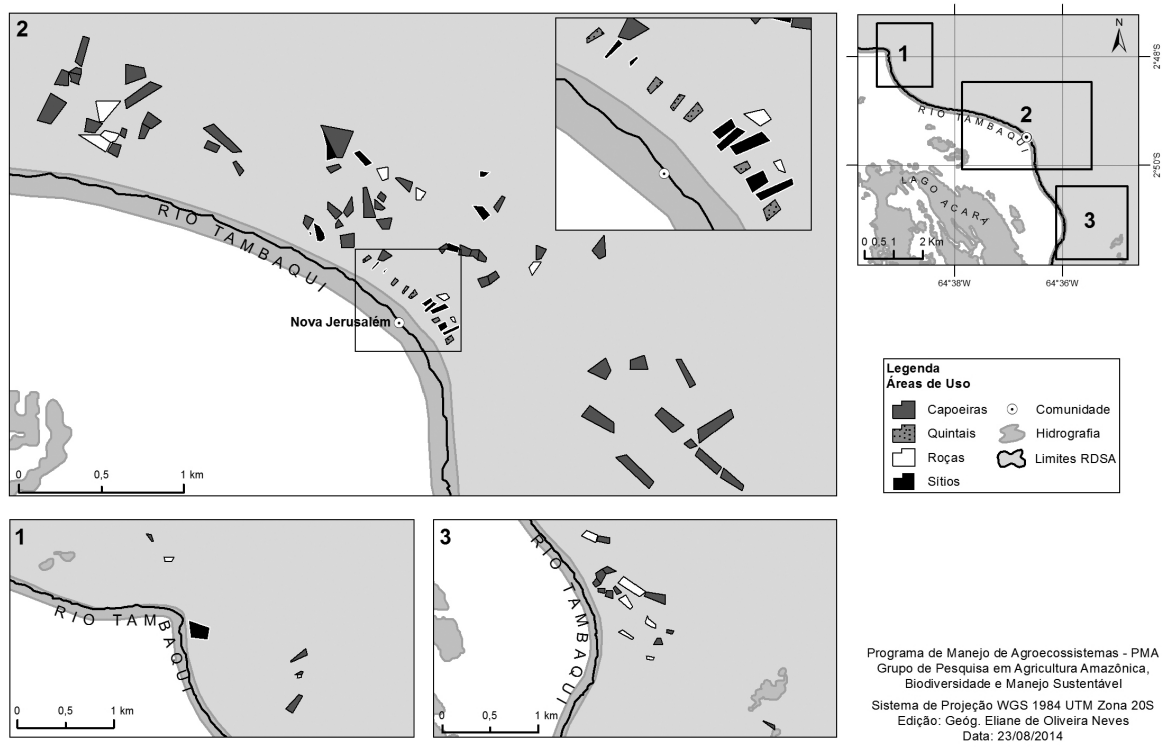

Em Nova Jerusalém cada agricultor apresentou uma média de 4,04 áreas com o tamanho médio de 0,56 ha de área. Assim como verificamos em Boa Esperança as análises de imagens na região da comunidade de Nova Jerusalém demonstraram as transformações na paisagem ao longo do tempo e as alterações na cobertura florestal (Figura 3).

As imagens revelam uma regeneração das áreas de uso, com prevalência de áreas de vegetação secundária (capoeira) em estágios mais avançados de regeneração, que somam $89,6 \%$ do total de área convertida, isso pode ser explicado pela intensificação da atividade pesqueira, observada no período em que a pesquisa foi realizada, que gera mais renda na comunidade, reduzindo o investimento nas atividades agrícolas. Ao mesmo tempo, uma análise dos resultados dos censos demográficos indica uma redução no número de moradores nesta comunidade, o que pode estar relacionado à diminuição das áreas de uso do solo que foram mapeadas nas imagens neste período: em 2002 
a população residente nesta comunidade era de 265 pessoas (IDSM 2002), em 2006 este número reduziu para 233 pessoas (IDSM, 2006) e em 2011 para 231 pessoas (IDSM, 2011). Além disso, a comunidade apresenta uma tendência para o desenvolvimento do extrativismo vegetal e comumente realiza o enriquecimento de sítios, o que também contribui para estes resultados, já que estas atividades reduzem a demanda para a abertura de novas áreas para o plantio de mandioca, e os sítios têm uso permanente.

Assim como em Boa Esperança as roças são destinadas ao plantio da mandioca e/ou macaxeira e espécies arbóreas de interesse econômico e ecológico que são deixadas no local, exemplos são as espécies de cedro e o mulateiro que tem sua madeira utilizada para construção de casas, canoas, balsas deixadas no roçado no momento em que estas áreas são estabelecidas. Os agricultores também investem no plantio de espécies frutíferas, como a pupunha, tucumã, a castanheira, açaí, dentre outras, no momento da abertura de novas áreas.

O enriquecimento de roçados em uso e recém-desmanchado é realizado com frequência nestas comunidades, já que espécies de interesse ecológico alimentício compõem a alimentação das famílias. Os agricultores ao colherem a roça madura, abandonam a área, entretanto, foram observados casos em que as famílias enriqueceram as áreas com estas espécies.

Nesta comunidade são as capoeiras com idade de pousio de até 4 anos que compõem a maior parte dos land use stages levantados, segundo os agricultores, estas áreas foram abertas pela primeira vez entre um e 10 anos atrás. Espécies de embaúbas (Cecropia spp.) e frutíferas também foram observadas.

Diferente da outra comunidade, as capoeiras são de difícil acesso, mesmo pelas trilhas, as áreas apresentam uma vegetação com intensa presença de lianas, e espécies com espinhos e arbustivas que dificultam a passagem. Estas características não impedem que os agricultores mantenham espécies frutíferas de interesse, como a banana e o abacaxi, nestas áreas. As espécies que mais se destacaram foram as bananeiras e abacateiros, além destas outras espécies são cultivadas nestas áreas em menor proporção para se desenvolverem durante o período de pousio, exemplos são a pupunha, o limão e o cupuaçu. Estas práticas tornam a paisagem mais heterogênea criando um mosaico diversificado com estratos de vegetação que se inter-relacionam, formando um sistema integrado à floresta.

$\mathrm{O}$ retorno às capoeiras geralmente acontece quando os mesmos as escolhem para o estabelecimento de uma nova roça, ou quando esta se encontra em um estágio de regeneração (superior a 2 anos) que permite o acesso rápido à área para colher os frutos. Apesar disso, alguns agricultores disseram visitar a área algumas vezes, mesmo com difícil acesso para fazer um manejo de espécies 
de interesse. Já quando o plantio de espécies é realizado no caminho ou trilha que conduz até a área do roçado, nota-se um manejo constante destas espécies.

Os sítios são intensamente utilizados nesta comunidade. Os agricultores ao se deslocarem até os locais de roças transitam pelos sítios para colherem os frutos ou realizarem a manutenção destas áreas. O investimento no sítio é realizado constantemente com o plantio de espécies frutíferas variadas.

O termo "Quintais" foi utilizado para descrever um tipo de uso do solo agrícola (land use stage) destinadas ao plantio de frutas de fácil acesso. Neste espaço, geralmente localizados atrás das casas, podem ser encontrados plantios de hortaliças e criações de animais (principalmente galinhas e porcos). É um espaço de socialização entre os moradores da comunidade, onde se tem a preparação de alimentos, e onde são costuradas as malhadeiras (redes de pesca). A denominação de quintal foi utilizada apenas entre os moradores de Nova Jerusalém. Em Boa Esperança, os quintais se misturam aos sítios, sendo assim este termo não é comumente adotado entre os moradores desta comunidade. Estes espaços se diferem dos sítios principalmente pela diversidade de usos que lhe é dado.

\section{Aspectos do manejo agrícola na área de estudo}

Nesta parte que segue discutimos alguns dos principais fatores que influenciam na escolha entre uma área de mata bruta ou de capoeira para estabelecer uma nova área de plantio (roça), além disso, apresentamos as práticas do manejo agrícola mais comuns nas comunidades estudadas e aspectos técnicos que favorecem a agrobiodiversidade.

O termo "mata virgem" ou "mata bruta" é utilizado constantemente entre os moradores das comunidades ribeirinhas estudadas, para designar áreas de floresta em sucessão ecológica mais avançada, entretanto, apesar destes termos remeterem a conceitos de floresta de vegetação primária, estas áreas não necessariamente são caracterizadas por este tipo de vegetação. Para a grande maioria destes moradores estas áreas designadas de mata virgem ou bruta, não estariam necessariamente "intocadas", mas provavelmente não são utilizadas há muitos anos, sendo as últimas utilizações por outros povos, indígenas ou moradores mais antigos desta região. Isso pode ser verificado em falas de agricultores como: "Aqui era mata virge, meu pai que derrubô, nessa época eu era bem jitinho (pequeno) e ajudei ele a capiná.... mas essa terra aqui já foi terra de outros moradô.. mais antigo, acho que já morou índio aqui porque tem essas peças deles aí...”(morador da Boa Esperança). 
A caracterização da vegetação florestal como mata virgem, pelos moradores, também é dada quando se tem um período de pousio longo (geralmente superior a 10 anos) associado a uma primeira utilização pela família que estabeleceu o plantio. Esse período confere a esta área uma aparente fitofisionomia de floresta primária, por estar em um estágio de sucessão avançado da floresta. O termo capoeira, no entanto, é muito comum para designar uma área de vegetação secundária, em estágio inicial, médio ou avançado de regeneração, é caracterizado assim para áreas recém abandonadas após o desmanche do roçado, antes de se constituírem em áreas de mata bruta.

Quando questionados sobre a preferência pela abertura de áreas em mata bruta ou capoeiras, os moradores explicam que a derrubada de uma área de mata bruta é mais trabalhosa em termos de esforço físico. Por outro lado, a produtividade da área é maior, as espécies apresentam maior vigor, e a manutenção da área é mais fácil de ser realizada, precisando de menos capinas para manter a área limpa. A regeneração em áreas de mata ocorre com espécies da regeneração natural, com menor frequência de espécies daninhas.

Por outro lado, às áreas de capoeira, exigem um esforço físico menor para abrir, quando comparado a abertura das áreas de mata, mas segundo os agricultores, o empenho na manutenção da área é maior porque a rebrota de espécies daninhas (conhecidas pelos agricultores como espécies de mato) ocorre com maior abundância exigindo capinas com maior frequência nestas áreas (três vezes mais do que em área de mata). Os moradores também explicam que as áreas de roça oriundas da capoeira tendem a ter uma produtividade menor, já que segundo eles as mandiocas nas roças em áreas de mata "tanto carrega como engrossa mais". Essa produtividade geralmente está associada ao número de vezes que a área já foi utilizada e ao período que a área esteve em pousio entre uma utilização e outra. Esses mesmos padrões foram indicados por Richers (2010) ao examinar a preferência pelo estabelecimento de roças em áreas de mata em relação à capoeira na região.

Em Schmidt (2003) foi identificada a preferência dos agricultores por implementar as roças nas áreas de capoeira. Isso pode ser explicado tanto pelo distanciamento das áreas de mata bruta da comunidade como também pela preferência de alguns agricultores em andar menos para acessar as áreas de roças, priorizando as áreas nas proximidades das comunidades, já que normalmente precisam carregar cargas de mais de $40 \mathrm{~kg}$ de raízes de mandioca nas costas até suas casas de farinha. Pereira et al. (2010) identificaram na região que o tipo de solo (arenosos), o risco de inundação, a distância da comunidade e o tipo de vegetação local (se mata bruta ou capoeira) são fatores que influenciaram na escolha das 
áreas para o estabelecimento de sistemas produtivos e na escolha de qual o tipo de sistema agrícola será estabelecido. Isso demonstra que a escolha pelo ambiente e o tipo de uso escolhido para a área são influenciados por diversos fatores.

De acordo com relatos de alguns agricultores o retorno às áreas de capoeira ocorre em algum momento, independente da opção pelo estabelecimento de plantios em áreas de mata, ou seja, mesmo que eles derrubem uma área de mata bruta para o estabelecimento de cultivos em um ano, em anos seguintes eles tendem a retornar para uma área já utilizada. Uma maior frequência de visita às capoeiras abandonadas para manutenção das espécies que foram plantadas foi observada no momento em que a roça foi desmanchada. Áreas de capoeiras próximas às áreas de roçado são visitadas constantemente, seja para o enriquecimento, seja para a colheita de espécies de interesse.

Em alguns casos, observou-se que os moradores optam pela abertura de áreas em capoeiras, promovendo uma rotatividade de uso nestas áreas integrada com períodos de pousio que permitem uma regeneração média das áreas florestais.

“... a minha vida inteira eu planto nestas cinco áreas, eu vou plantando de tempos em tempos em cada uma, na ordem mesmo, eu planto nelas assim seguidas, na primeira e na última delas eu tenho roça e nas outras que ficam no meio delas eu tenho capoeiras, depois que eu desmanchar as roças, aquelas áreas vão virar roça e essas aqui capoeira e enquanto eu vou fazendo assim, a terra das capoeiras vai descansando uns três anos, aí a terra não fica muito cansada e as planta vão dando boa.... e eu não fico derrubando mata por aí..” (morador da comunidade de Boa Esperança)

Uma outra prática de manejo que é utilizada por alguns agricultores é a replanta, considerada como o plantio consecutivo da área de roça, sem o período de pousio. Esta prática tem sido cada vez mais rara entre as famílias e geralmente, quando os agricultores a fazem, optam por realizá-la, por no máximo, duas vezes consecutivas, e mais raramente por três vezes, sendo realizada concomitante ao início da colheita na área de roçado. Estes resultados também foram verificados em Richers (2010).

A replanta foi verificada, em algumas vezes, associada a eventos naturais da região, tal como quando se tem o alagamento de uma área no período das cheias que leva a perda da produção e os agricultores não querem deixar de plantar. Nestes casos, eles costumam esperar passar o período de alagamento e que o solo não esteja encharcado para estabelecer o novo plantio. Isso pode ser verificado em falas de agricultores como: "A área tá toda nágua (na água)... a cheia fez eu perder tudo que tinha plantado, aí depois que secar bem a terra tô pensando em replantá pra vê se consigo alguma planta (mandioca) e não ficá sem farinha..” (morador de Nova Jerusalém). 
Geralmente a opção pela não realização do replantio se justifica no conhecimento que os mesmos demonstraram sobre o processo de aceleração do esgotamento do solo, quando o período de pousio não é adotado. Isso é verificado em falas de agricultores como: “... depois de umas três planta a mandioca já não dá boa mais, a batata não engrossa, então é melhor não plantá e escolher outro lugar que a terra está mais descansada" (morador de Nova Jerusalém). “... eu desmancho a roça, deixo a terra descansá pelo menos uns quatro, cinco ano se eu tiver mais área pra plantá, porque se fica fazendo replanta, a terra vai ficando fraca, e a mandioca não dá boa mais..." (morador de Boa Esperança).

Escolhas como as apresentadas acima partem das observações e cuidados dos próprios moradores, que devido à importância da agricultura para a manutenção de suas famílias, e à reprodução do grupo social em geral, zelam por suas áreas para garantir produções futuras. Esta lógica, guiada pelo saber local, vai de encontro a proposta do uso sustentado dos recursos naturais, e assim podemos argumentar que contribui para a continuidade dos serviços ecológicos no local (LIMA, 2008).

\section{Estratégias de deslocamento e escoamento da produção no interior das comunidades}

Os caminhos são trilhas feitas pelos próprios moradores, que dão acesso às áreas de plantio de vários agricultores; a paisagem ao longo destes caminhos é bastante heterogênea composta por mosaicos diversificados de usos do solo e espécies. As áreas de cultivo se distribuem em toda a extensão da comunidade, sendo algumas destas áreas distantes das casas de farinha e da comunidade. Estas áreas mais distantes das casas, geralmente, possuem dois tipos de vias de acesso: os "caminhos" que conduzem às áreas produtivas de diversos agricultores, e os igarapés (pequenos rios) ou áreas de igapó (mata alagada). O acesso às áreas pelos igarapés é utilizado principalmente no período das cheias, quando o nível da água permite o deslocamento da rabeta ${ }^{9}$ ou da canoa ${ }^{10}$ por terrenos mais rasos. Nos períodos de vazante, o deslocamento com as sacas de farinha ou com o paneiro ${ }^{11}$

\footnotetext{
9 Rabeta é um veículo utilizado pelos ribeirinhos para o deslocamento das famílias, consiste em uma canoa de madeira onde se acopla um motor de popa de baixa potência.

10 Canoa é um veículo de madeira movido a remo utilizado para deslocamento dos moradores ribeirinhos

11 Paneiro é um cesto confeccionado com fibra vegetal pelos próprios moradores; é um tipo de artesanato em cestaria, muito utilizado para o transporte de tubérculos de mandioca e frutas das áreas de plantio até as casas de farinha ou outro local de destino destes. O paneiro apresenta a vantagem de permitir uma melhor adaptação ao transporte, por possuir alças laterais e uma alça frontal que permite uma melhor acomodação do cesto nas costas do agricultor.
} 
é realizado por estes "caminhos". Nas comunidades estudadas o deslocamento dos agricultores às suas áreas de plantio é frequente, principalmente no período entre os meses de julho e setembro (estação seca), considerado o período de maior abertura de áreas nas comunidades para o plantio de roçados e colheita.

A comunidade Boa Esperança devido a sua especialidade na produção de farinha tem o acesso às áreas produtivas (roças, capoeiras e sítios) realizados mais intensamente nestes meses e ao longo dos dias de semana. Com a finalidade de facilitar o acesso e otimizar o deslocamento com os paneiros no percurso entre as áreas produtivas e as casas de farinha, os moradores realizam a capina e a limpeza dos caminhos (trilhas) periodicamente. Estes caminhos são uma particularidade de algumas comunidades, como é o caso de Boa Esperança. Em Nova Jerusalém as trilhas que conduzem até as áreas produtivas desta comunidade não são bem definidas como em Boa Esperança, uma vez que a manutenção das trilhas geralmente é feita no momento em que se deslocam até estas áreas, para colheita de frutas ou manutenção das áreas de roça, o que também pode ser explicado pela principal atividade desta comunidade ser a atividade pesqueira.

Em Boa Esperança, em função desta distância (em torno de três quilômetros a das áreas produtivas até a comunidade) e da dificuldade de transporte da mandioca até a comunidade é que muitos moradores preferem transportar os tubérculos em paneiros até as casas de farinha próximas às comunidades, ao invés de produzir a farinha em locais distantes da comunidade. Essa preferência pode ser justificada pelo fato das sacas, terem um peso maior (em torno de 70 a $80 \mathrm{~kg}$ ) do que os paneiros cheios (em torno de 40 a $60 \mathrm{~kg}$ ) e pelo fato destes últimos serem mais facilmente transportados. Nesta comunidade, durante a época da cheia, os igarapés e áreas de igapó facilitam o acesso por meio de canoa ou rabeta a alguns roçados bem distantes da área da comunidade, esse fato permitiu que os agricultores abrissem um grande número de roçados em área de mata.

Por outro lado, em Nova Jerusalém não foi possível se conhecer profundamente as preferências dos agricultores sobre as formas de transporte da mandioca ou da farinha, tendo em vista que algumas áreas estavam alagadas durante o período que em foi desenvolvida a pesquisa. Entretanto, visitando-se as áreas produtivas encontramos uma distância em torno de um quilômetro e meio da área da comunidade até as áreas de cultivo. Embora a comunidade estivesse no período de cheia, o deslocamento com as sacas não foi muito observado, de forma geral, observou-se o processamento da mandioca nas casas de farinha localizadas na área da comunidade. 


\section{DISCUSSÃO}

\section{A agricultura migratória: corte queima, cultivo e pousio}

Pesquisas realizadas por van Vliet et al. (2013) demonstraram que o uso do solo na agricultura de pequena escala tem como principais tendências a diminuição das florestas naturais, o aumento dos pousios gerenciados em sistemas agroflorestais e o aumento das áreas de pastagem. Este tipo de agricultura é caracterizado por sistemas complexos de produção que combinam a agricultura migratória e de corte e queima. A variação entre os dois sistemas é influenciada por particularidades das comunidades e famílias que fazem o uso da terra.

Nas comunidades estudadas o sistema identificado apresenta maior tendência para o sistema de cultivo de agricultura migratória, já que o plantio nas áreas agrícolas é realizado a partir do corte, derruba e queima das áreas, utilizando-se do período de pousio de 2 anos ou mais, entre um uso e outro. $\mathrm{Na}$ maioria dos casos este período tem permitido as famílias o uso das áreas por anos, sendo raros os casos onde a prática é adotada sem este período.

O período do pousio é considerado a etapa mais importante na prática de agricultura migratória, por ser nesta fase que se reproduzem os processos ecológicos dos ecossistemas florestais. A resiliência do ambiente está inteiramente relacionada a este período, é nesta fase que o sistema irá restabelecer as condições para manutenção das funções básicas ecológicas que permitem que o ecossistema restabeleça (KLEINMAN et al., 1995, MERTZ et al., 2009).

A demanda por terras cultiváveis tem sido um dos fatores responsáveis pela redução no período de pousio (METZGER, 2002) e isso afeta os processos ecológicos de regeneração florestal das florestas secundárias. A desestabilização entre as fases de uso (cultivo) e período de abandono da área (pousio) pode ser considerada uma forma de impacto negativo, já que não permite o período mínimo para restabelecimento das características do ecossistema. Diversos estudos já tratam dos impactos sobre a biodiversidade ocasionados por este tipo de prática, e o que se nota é que quando períodos de pousio são intercalados com períodos de uso das áreas, essa forma de uso do solo torna-se sustentável (KLEINMAN et al., 1996; MERTZ et al., 2009).

Nas comunidades estudadas o período de tempo que a área permanece em abandono é influenciado pelo número de áreas que o produtor possui sobre sua gestão, pela vocação produtiva da família em relação ao plantio para subsistência, e pela obtenção de outras fontes de renda, como por exemplo, a 
pesca, o extrativismo e a caça, que reduzem a pressão sobre as áreas produtivas e assegura a subsistência com fontes alternativas, além da agricultura de mandioca.

Operíodo adequado de pousioéum fator determinante para a sustentabilidade e recuperação do ambiente. A redução da sustentabilidade do sistema relacionase aos impactos com mudanças socioambientais, bem como aspectos políticos e culturais que refletem sobre a dinâmica agrícola. Em Ribeiro Filho et al. (2013) encontramos uma revisão de literatura global com discussões que tratam dos impactos da agricultura de corte e queima (coivara) nos solos. Essa prática "não seria insustentável per se em relação à dinâmicas de solos”. Pressões demográficas, tais como crescimento populacional associado as mudanças ambientais globais podem influir sobre as sociedades que praticam este tipo de agricultura, levando ao aumento do número de ciclos de cultivo ao qual a área é submetida antes desta ser abandonada em pousio. Estas pressões refletem sobre as propriedades físicas do solo e consequentemente comprometem a resiliência destes sistemas.

Nas regiões de estudo, com ambientes de paleovárzea, assim como a presença de Terra Preta de Índio ${ }^{12}$ favorecem o tempo de pousio, que mesmo sendo menor em relação a outras regiões, seja suficiente para o restabelecimento de uma floresta secundária, favorecendo o descanso do solo e permitindo a sustentabilidade das áreas produtivas. Relatos dos agricultores indicam que o tempo de pousio observado é suficiente para a recuperação do solo: "Esse tempo de uns três, quatro anos que a terra fica descansando já dá pra plantar, depois se ficá usando mais a terra é que ela começa a ficá fraca, aí já é bom mudar pra outra mata...." (morador de Nova Jerusalém). "A terra fica descansada com uns quatro, cinco anos aí já tá forte pra plantá outra roça..." (morador de Boa Esperança).

A análise sobre os diferentes tipos de uso das áreas, por estas comunidades, levou em consideração a vocação produtiva que cada comunidade possui em relação a atividade agrícola. Outros fatores também foram importantes neste contexto, como a construção histórica das comunidades, os motivos que levaram a sua formação, o desenvolvimento das famílias (reprodução familiar), suas especialidades na produção, principais recursos explorados para a subsistência, bem como as fontes de renda que compõem a renda familiar. Todos estes fatores influenciam nas diversificadas formas de manejo agrícola que foram encontradas nas comunidades e são importantes questões a serem consideradas em discussões como esta.

12 As terras pretas são presentes na bacia Amazônica, aparecendo em manchas isoladas ou extensas, e que são consideradas de origem antrópica relacionada ao manejo indígena passada. Terras pretas diferem de solos adjacentes por serem extremamente ricos em matéria, com uma fertilidade elevada, e normalmente apresenta a presença de artefatos líticos e/ou vestígios cerâmicos (TEIXEIRA et al., 2009). 
As áreas convertidas para fins agrícolas, por estarem integradas ao ecossistema florestal destas comunidades, são dificilmente identificadas isoladamente através das imagens de satélite (principalmente em imagens de baixa resolução). A heterogeneidade destas áreas é claramente visualizada em campo, quando observadas as áreas de uso. Quando sobrepostas às áreas mapeadas em campo com as imagens de satélite, destacaram-se as áreas de roçados, em Boa Esperança, resultado da especialização da comunidade na produção da farinha de mandioca. Por sua vez, em Nova Jerusalém se destacaram áreas de vegetação secundária em regeneração, o que está relacionado à atividade pesqueira predominante nesta comunidade, no período da pesquisa.

Por fim, é possível observar que os sistemas agrícolas estabelecidos nestas comunidades favorecem a geração de agrobiodiversidade local (SCHMIDT, 2003; BARCELOS, 2015) o qual é longamente reconhecida como uma parte essencial da biodiversidade global (BROOKFIELD et al., 2002; THRUPP, 2000). O hábito dos moradores de enriquecimento das áreas agrícolas com espécies de interesse alimentício, medicinal, além de outras espécies com outros fins, são os principais fatores que contribuem para a geração da agrobiodiversidade destas áreas.

\section{CONSIDERAÇÕES FINAIS}

A agricultura continuamente praticada integrada à floresta, assim como a prática do pousio em tempo considerado suficiente para a regeneração florestal em condições de se estabelecer um novo ciclo de plantio são indicativos da sustentabilidade, a partir da perspectiva produtiva, do sistema de agricultura migratória nos locais estudados.

Verificamos ao longo desta pesquisa que o uso e manejo do solo acontecem de forma dinâmica, com modificações constantes no espaço nas áreas produtivas, resultantes da fase de uso do solo que estará presente no momento. Os sistemas agrícolas praticados nas comunidades estudadas caracterizam-se por uma intensa utilização dos recursos naturais. Em Boa Esperança a vocação produtiva das famílias e a especialização dos moradores para a produção da farinha de mandioca para comercialização, conferem a esta comunidade o manejo intensivo de suas áreas. Os agricultores se destacam por apresentar um perfil experimentador voltado para o manejo destas áreas. As áreas produtivas embora intensamente utilizadas são manejadas utilizando-se do período de pousio entre um uso e outro.

Por outro lado, em Nova Jerusalém as famílias são voltadas a pesca e ao extrativismo vegetal e animal, sendo a agricultura uma atividade secundária voltada praticamente para a subsistência, mas também de grande importância. 
A dinâmica das atividades agrícolas é semelhante à praticada em Boa Esperança, entretanto, é menos intensiva e especializada pelo fato dos moradores investirem mais em outras atividades. O enriquecimento dos sistemas produtivos é constante sendo voltado ao plantio de espécies frutíferas.

$\mathrm{O}$ uso consorciado à floresta bem como o enriquecimento com espécies frutíferas em todas as formas de uso (roça, capoeira, sítios e quintais) encontradas tem garantido, até o momento, a sustentabilidade desta prática nestas comunidades, no sentido que tem permitido os agricultores garantir uma produção contínua que atende a suas necessidades. De maneira geral, percebemos uma estreita relação dos moradores com o ambiente local aonde os mesmos realizam o manejo das áreas agrícolas seguindo um processo semelhante ao de sucessão ecológica.

Assim, as áreas produtivas vão sendo utilizadas e desenvolvidas em formas que se aproximam dos ecossistemas naturais. Esse processo permite a continuidade de uso dos solos, ao longo de anos, evitando sua degradação e esgotamento e proporcionando condições ao desenvolvimento das famílias e a manutenção de suas áreas produtivas. A produtividade e a conservação além de serem influenciadas por aspectos socioeconômicos, também se relacionam aos tipos de uso e manejo dos solos das áreas produtivas, a vocação produtiva e o modo de vida das famílias.

\section{AGRADECIMENTOS}

Aos moradores da Reserva Amanã pela grande contribuição, com as informações e disponibilidade de acompanharmos, nas visitas a campo, aos assistentes de campo e técnicos do Programa de Manejo de Agroecossistemas/ IDSM, que apoiaram as ações durante a coleta de dados, aos pesquisadores do Grupo de Pesquisa em Agricultura Amazônica, Biodiversidade e Manejo Sustentável e ao Grupo de Pesquisa Organização social e manejo participativo dos recursos renováveis e não renováveis na Amazônia/IDSM que contribuíram com as discussões e revisões, a Eliane Neves pela elaboração de mapas, ao Jefferson Ferreira pelo apoio nas análises.

\section{REFERÊNCIAS}

ADAMS, C. et al. A. O pão da terra: da invisibilidade da mandioca na Amazônia. In: ADAMS, Cristina; MURRIETA, Rui; NEVES, Walter (Orgs.). Sociedades caboclas amazônicas: modernidade e invisibilidade. São Paulo: Annablume, 2006. 
ALENCAR, E. F. Estudo da ocupação humana e mobilidade geográfica de comunidades rurais da Reserva de Desenvolvimento Sustentável Amanã, RDSA. Relatório Final. Tefé. 2007.168p.

ALENCAR, E. F. Dinâmica territorial e mobilidade geográfica no processo de ocupação humana. UAKARI, v.6, n.1, p.39-58, 2010.

BARCELOS, L. E. A diversidade florística nos quintais em terra preta de índio e solos menos antrópicos em paleovárzea e na terra firme, Médio Solimões, Amazonas, Brasil. 2015. Dissertação (Mestrado em Botânica), Instituto Nacional de Pesquisas da Amazônia. Manaus, 2015.

BERNARD, H. R. Research methods in anthropology: Qualitative and Quantitative Approaches. Lanham, MD: Rowman Altamira, 2011.

BRADY, N. C. Alternatives to slash-and-burn: a global imperative. Agriculture, Ecosystems \& Environment, v. 58, n. 1, p. 3-11, 1996.

BRANCALION, P. H. S. et al. Estratégias para auxiliar na conservação de florestas tropicais secundárias inseridas em paisagens alteradas. Boletim do Museu Paraense Emílio Goeldi. Ciências Naturais, v. 7, n. 3, p. 219-234, 2012.

BROOKFIELD, H. et al. Cultivating biodiversity: understanding, analysing and using agricultural diversity. Rugby Warwickshire: ITDG Publishing, 2002.

CHAZDON, R. L. Regeneração de florestas tropicais. Boletim do Museu Paraense Emílio Goeldi. Ciências Naturais, v. 7, n. 3, p. 195-218, 2012.

EMPERAIRE, L.; ELOY, L. A cidade, um foco de diversidade agrícola no Rio Negro (Amazonas, Brasil)? Boletim do Museu Paraense Emílio Goeldi. Ciências Humanas v. 3, n. 2, p. 195-211, 2008.

FEARNSIDE, P. M. Agricultura na Amazônia: Tipos de agricultura, padrão e tendências. Cadernos NAEA, v. 10, p. 197-252, 1989.

FEARNSIDE, P. M. A floresta Amazônica nas mudanças globais. Manaus, INPA 134p. 2003.

FEARNSIDE, P. M. Deforestation in Brazilian Amazonia: history, rates, and consequences. Conservation biology, v. 19, n. 3, p. 680-688, 2005.

FEARNSIDE, P. M. Desmatamento na Amazônia: dinâmica, impactos e controle. Acta Amazônica, v. 36, n. 3, p. 395-400, 2006.

FERREIRA, L. V.; VENTICINQUE, E.; ALMEIDA, S. O desmatamento na Amazônia e a importância das áreas protegidas. Estudos avançados, v. 19, n. 53, p. 157-166, 2005. 
IDSM. Instituto de Desenvolvimento Sustentável Mamirauá. Banco de dados do levantamento sociodemográfico da Reserva de Desenvolvimento Sustentável Amanã, 2002. Tefé-AM: IDSM, 2002.

IDSM. Instituto de Desenvolvimento Sustentável Mamirauá. Banco de dados do levantamento sociodemográfico da Reserva de Desenvolvimento Sustentável Amanã, 2006. Tefé-AM: IDSM, 2006.

IDSM. Instituto de Desenvolvimento Sustentável Mamirauá. Banco de dados do levantamento sociodemográfico da Reserva de Desenvolvimento Sustentável Amanã, 2011. Tefé-AM: IDSM, 2011.

IRION, G. et al. Development of the Amazon valley during the Middle to Late Quaternary: sedimentological and climatological observations. Amazonian Floodplain Forests. [S.1.]: Springer, 2011. p. 27-42.

KLEINMAN, P. J. A.; PIMENTEL, D.; BRYANT, R. B. The ecological sustainability of slash-and-burn agriculture. Agriculture, Ecosystems \& Environment, v. 52, n. 2, p. 235-249, 1995.

KLEINMAN, P. J. A.; BRYANT, R. B.; PIMENTEL, D. Assessing ecological sustainability of slash-and-burn agriculture through soil fertility indicators. Agronomy Journal, v. 88, n. 2, p. 122-127, 1996.

LAURANCE, W. F. et al. Deforestation in Amazonia. Science (New York, NY), v. 304, n. 5674, p. 1109, 2004.

LIMA, D. de M. A economia doméstica em Mamirauá. In: ADAMS, Cristina; MURRIETA, Rui.; NEVES, Walter. (Orgs.). Sociedades Caboclas Amazônicas: modernidade e invisibilidade. São Paulo: Annablume /Fapesp, 2006, p. 145-172.

LIMA, D. de M. Firmados na terra: a produção do significado de território em dois quilombos de Minas Gerais. In: 32 ENCONTRO ANUAL DA ANPOCS, 2008, Caxambu. Anais... Caxambu, MG, 2008.

LIMA, D. de M.; STEWARD, Angela M.; RICHERS, Bárbara T. Trocas, experimentações e preferências: um estudo sobre a dinâmica da diversidade da mandioca no Médio Solimões, Amazonas. Boletim do Museu Paraense Emılio Goeldi. Ciências Humanas, 2012.

LIMA, P. G. C. et al. Agrobiodiversity Agrobiodiversidade e etnoconhecimento na Gleba Nova Olinda I, Pará: interações sociais e compartilhamento de germoplasma da mandioca (Manihot esculenta Crantz, Euphorbiaceae). Boletim do Museu Paraense Emílio Goeldi. Ciências Humanas, v. 8, n. 2, p. 419-433, 2013. 
MASSOCA, P. E. dos S. et al. Dinâmica e trajetórias da sucessão secundária na Amazônia central. Boletim do Museu Paraense Emílio Goeldi. Ciências Naturais, v. 7, n. 3, p. 235-250, 2012.

MERTZ, O. et al. Swidden change in Southeast Asia: understanding causes and consequences. Human Ecology, v. 37, n. 3, p. 259-264, 2009.

METZGER, J. P. Landscape dynamics and equilibrium in areas of slash-and-burn agriculture with short and long fallow period (Bragantina region, NE Brazilian Amazon). Landscape Ecology, v. 17, n. 5, p. 419-431, 2002.

MYERS, N. Tropical forests: the main deforestation fronts. Environmental Conservation, v. 20, n. 01, p. 9-16, 1993.

NEVES, W. A et al. Coivara: cultivo itinerante na floresta tropical. Ciência Hoje, v. 50 , p. $26-30.2012$.

NODA, S. do N. et al. Paisagens e etnoconhecimentos na agricultura Ticuna e Cocama no alto rio Solimões, Amazonas. Boletim do Museu Paraense Emílio Goeldi. Ciências Humanas, v. 7, n. 2, p. 397-416, 2012.

PADOCH, C.; PINEDO-VASQUEZ, M. Saving Slash-and-Burn to Save Biodiversity. Biotropica, v. 42, n. 5, p. 550-552, 2010.

PEDROSO JUNIOR, N. N.; MURRIETA, R. S. S.; ADAMS, C. A agricultura de corte e queima: um sistema em transformação. Boletim do Museu Paraense Emílio Goeldi. Ciências Humanas, v. 3, n. 2, p. 153-174, 2008.

PERALTA, N.; LIMA, D. de M. A comprehensive overview of the domestic economy in Mamirauá and Amanã in 2010. UAKARI, v. 9, n. 2, p. 33-62, 2013.

PEREIRA, K. J. C. et al. Saber tradicional, agricultura e transformação da paisagem na Reserva de Desenvolvimento Sustentável Amanã, Amazonas. UAKARI, v. 2, n. 1, p. 9-26, 2010.

PIÑEDO-VASQUEZ, M.; PADOCH, C.; INUMA, J. C. Identifying and understanding agricultural, agroforestry and forest management systems and techniques practiced in Mamirauá. Tefé, Sociedade Civil Mamirauá, 1996.

POSEY, D. A. Manejo da floresta secundária capoeira, campos e cerrados (Kayapó). In: RIBEIRO, Darci (Ed.) Suma Etnológica Brasileira (Volume 1: Etnobiologia). Belém: Editora da UFPA, 1997. p.199-213. 
QUEIROZ, H. L. A reserva de desenvolvimento sustentável Mamirauá. Estudos avançados, v. 19, n. 54, p. 183-203, 2005.

QUEIROZ, H. L.; PERALTA, Nelissa. Reserva de Desenvolvimento Sustentável: Manejo integrado dos recursos naturais e gestão participativa. In: GARAY, Irene; BECKER, Bertha K (Orgs.). Dimensões humanas da biodiversidade, p. 447-476, 2006.

RIBEIRO FILHO, A. A.; ADAMS, C.; MURRIETA, R. S. S. The impacts of shifting cultivation on tropical forest soil: a review. Boletim do Museu Paraense Emílio Goeldi. Ciências Humanas, v. 8, n. 3, p. 693-727, 2013.

RICHERS, B. T. T. Agricultura migratória na várzea: ameaça ou uso integrado? UAKARI, v. 6, n. 1, p. 27-37, 2010.

RIVERO, S. et al. Pecuária e desmatamento: uma análise das principais causas diretas do desmatamento na Amazônia. Nova economia, v. 19, n. 1, p. 41-66, 2009.

ROBERT, P. De et al. A beleza das roças: agrobiodiversidade MebêngôkreKayapó em tempos de globalização. Boletim do Museu Paraense Emilio Goldi. Ciências Humanas, v. 7, n. 2, p. 339-369, 2012.

ROBERT, P. De; LÓPEZ, C. Agriculturas amazônicas: cultivando plantas, saberes, paisagens e ideias. Boletim do Museu Paraense Emílio Goeldi. Ciências Humanas, v. 7, n. 2, p. 289-292, 2012.

SANCHEZ, P. A. et al. Alternatives to slash and burn: challenge and approaches of an international consortium. In: PALM, Cheryl A. et al. (Eds.). Slash and Burn Agriculture: The Search for Alternatives, [S.1.]: New York: Columbia University Press, 2005.

SCHMIDT, M. J. Farming and patterns of agrobiodiversity on the Amazon floodplain in the vicinity of Mamirauá, Amazonas, Brazil. 210f. 2003. Thesis (Master of Science) - University of Florida, Gainesville, 2003.

STEWARD, A.M., LIMA, D. M. Interações na roça: por uma ecologia das práticas da produção de mandioca no médio Solimões, Amazonas. In: Reunião da Antropologia Brasileira, 29., Universidade Federal do Rio Grande do Norte, Natal, 2014.

TEIXEIRA, W. G. et al. As terras pretas de índio da Amazônia: sua caracterização e uso deste conhecimento na criação de novas áreas. Manaus: Embrapa Amazônia Ocidental, 2009. 
THRUPP, L. A. Linking agricultural biodiversity and food security: the valuable role of agrobiodiversity for sustainable agriculture. International affairs, v. 76, n. 2, p. 283-297, 2000.

VALSECCHI, J.; AMARAL, P. V. Do A. Perfil da caça e dos caçadores na Reserva de Desenvolvimento Sustentável Amanã, Amazonas, Brasil. UAKARI, v. 5, n. 2, p. 33-48, 2009.

VAN VLIET, N. et al. "Slash and Burn" and "Shifting" Cultivation Systems in Forest Agriculture Frontiers from the Brazilian Amazon. Society \& Natural Resources, v. 26, n. 12, p. 1454-1467, 2013.

VENTURATO, R. D.; PEREIRA, K. J. C. Aspects of food soverign and labor sharing in domes in domestic units at the Mamirauá and Amanã sustainable developement reserves. UAKARI, v. 6, n. 2, p. 21-33, 2010. 